материалов. К числу таких материалов относятся переводческие упражнения и учебные тексты.

Считаем, что наиболее действенными методами исследования предлагаемой методики обучения студентов - лингвистов письменному переводу англоязычных текстов общественно - политического содержания на русский язык, которые позволят представить изучаемый материал в единстве общего и отдельного, выявить закономерности переводческих процессов и разработать критерии качества перевода, являются следующие: сравнительно-сопоставительный метод, метод синхронного или диахронного анализа, метод структурно-семантического анализа; метод сопоставления дефиниций, метод контекстуального анализа, статистический метод определения количественных и процентных характеристик исследования англоязычных общественно - политических текстов, социолингвистический метод корреляции языковых и социальных явлений.

$$
* * *
$$

1. Алексеева, И.С. Профессиональное обучение переводчика: учебное пособие по устному и письменному переводу для переводчиков и преподавателей /И.С. Алексеева. - Издательство «Союз» - Санкт - Петербург, $2001-288$ c.

2. Гришенко, И.С. Обучение общественно-политической лексике английского языка в ҮII-ҮIII классах средней школы: специальность 13.00 .02 «Теория и методика обучения и воспитания (по областям и уровням образования)»: дис. на соискание ученой степени канд. пед. наук /И.С. Гришенко. -Киев, 1990. - 216 с.

3. Ежова, Л.М. Совершенствование методики обучения письменному переводу общественно-политических текстов на среднем этапе обучения в специализированных вузах: специальность 13.00 .02 «Теория и методика обучения и воспитания (по областям и уровням образования)»: дис. на соискание ученой степени канд. пед. наук /Л.М. Ежова. -Москва, 2003. - 235 с.

4. Зражевская, Т.А., Гуськова, Т.И. Трудности перевода общественно-политического текста с английского языка на русский: учебное пособие для вузов/ Т.А. Зражевская, Т.И. Гуськова. - М.: Издательство «Высшая школа»,1986. - 240 с.

5. Латышев, Л.К. Технология перевода /Л.К. Латышев. - М.: Издательство «НВИ Тезаурус», 2000. - 278 с.

6. Чужакин, А.П, Спирина, С.Г. Основы последовательного перевода и переводческой скорописи /А.П. Чужакин, С.Г. Спирина. - М.: Издательство «Экспримо», 2017. - 91 с.

\title{
Плащевая Е.В. \\ Использование современных технологий в обучении будущих врачей на занятиях по медицинской физике
}

ФГБОУ ВО «Амурская государственная медииинская академия»

(Россия, Благовещенск)

doi: 10.18411/trnio-01-2022-149

\section{Аннотация}

В статье рассматривается применение технологии модульного обучения при изучении дисциплины «Физика, математика». Проанализированы и сформулированы проблемы, возникающие при обучении студентов первого курса. Данные проблемы позволили обнаружить эффективные пути и технологии для улучшения организации процесса обучения будущих врачей. Приведён фрагмент технологической карты с пошаговой инструкцией по выполнению задания.

Ключевые слова: будущие врачи, формирование самостоятельности, обучение физике, процесс обучения, инструкция, современные технологии.

\section{Abstract}

The article discusses the application of modular learning technology in the study of the discipline "Physics, Mathematics". The problems arising during the training of first-year students are analyzed and formulated. These problems allowed us to discover effective ways and technologies to improve the organization of the training process of future doctors. A fragment of the technological map with step-by-step instructions for completing the task is given.

Keywords: future doctors, the formation of independence, teaching physics, the learning process, instructions, modern technologies. 
За последнее десятилетия образование претерпело существенные изменения, оно стало более гибким и мобильным. В основном это связано с появлением современных технологий обучения, которые постоянно совершенствуются.

Использование современных технологий в образовании удобно по ряду причин:

- во-первых, это делает студентов мобильными, то есть они могут получать дополнительную информацию не только непосредственно от преподавателя в учебном классе, но и в любых других местах, где есть доступ к Интернету;

- во-вторых, главным преимуществом является наличие возможности получения быстрой обратной связи, особенно если студент не смог присутствовать на занятии.

Современные технологии обучения направлены на оптимизацию и совершенствование процесса обучения, в их основе находятся такие важные показатели, как: мотивированность; простота; доступность; экономичность; результативность.

Особенно необходима мотивированность, благодаря ей раскрываются резервные возможности каждого студента в результате чего происходит повышение интереса к дисциплине. Также необходимо отметить, что обучение должно происходить в атмосфере сотрудничества. Для обеспечения результата обучения необходим высокий уровень достижения поставленной учебной цели каждым обучающимся.

Проанализировав уровень знания студентов первого курса лечебного и педиатрического факультетов выявились следующие проблемы:

- очень низкий пороговый уровень подготовки обучающихся по школьным предметам: физика, математика;

- разный уровень подготовки между первокурсниками, закончившими городские, сельские школы и медицинского училища;

- отсутствие заинтересованности в освоении дисциплины «Физика, математика»;

- отсутствие навыков самостоятельной работы к образовательному процессу.

Анализ данных проблем позволил обнаружить эффективные пути и технологии для организации обучения будущих врачей по дисциплине «Физика, математика» в условиях реализации федеральных государственных образовательных стандартов высшего образования. Самой эффективной технологией является - технология модульного обучения, она позволяет решить вопрос самостоятельной работы студентов в процессе изучения дисциплины «Физика, математика».

Преимущества технологии модульного обучения [1, с. 187]:

1) грамотное структурирование содержания обучения;

2) индивидуальный темп обучения;

3) гибкость предоставления учебного материала для самостоятельной работы обучающихся;

4) накопительный принцип оценивания работы студента;

5) гибкий график усвоения нового содержания в рамках освоения учебного материала по изучаемой дисциплине;

6) приспособление дидактической системы к индивидуальным возможностям и уровню базовой подготовки будущих врачей в процессе организации самостоятельной работы по учебной программе.

Использование технологии модульного обучения даёт возможность решить многие проблемы на занятиях по дисциплине «Физика, математика»:

- активизация познавательной деятельности;

- организация самостоятельного обучения;

- $\quad$ индивидуализация и дифференциация обучения;

- $\quad$ развитие интеллекта и самостоятельности в процессе обучения.

Сущность данной технологии состоит в том, что будущий врач самостоятельно достигает поставленных перед ним целей учебно-познавательной деятельности.

Технология модульного обучения предполагает: 
1) наличие технологической карты, которая необходима для организации самостоятельной работы студентов;

2) наличие инструкции, в которой описано пошаговое выполнение заданий;

3) контроль, который необходим для проверки письменных и устных заданий (форма контроля - любая).

Приведем фрагмент технологической карта регистрации ЭКГ с пошаговой инструкцией [3, с. 131].

Снятие ЭКГ в трех стандартных отведениях у пациента (инструкция).

1. Нажмите кнопку «њ». На индикаторе отображаются символы. При многократном нажатии кнопки выберите символ 3К. Символ «3К» обозначают регистрацию по трем каналам.

2. Нажмите кнопку «ФИЛЬТР». На индикаторе отображаются символы: «С», «Т», «F». При многократном нажатии кнопки выберите символ «F». Символ «F»- режекторный и антитремовый фильтры одновременно.

3. Выключите успокоение, нажав кнопку «>O $<»$. На индикаторе символ «| $»$ сменится на символ «-».

4. Нажмите кнопку « $\nabla »$.

5. Включите регистрацию ЭКГ, нажав кнопку «ПУСК/СТОП». На индикаторе устанавливается надпись: «ЭКГ». Через несколько секунд начнется запись ЭКГ. По окончании записи ЭКГ на индикаторе высвечивается измеренное значение ЧСС и производится печать отведений. При необходимости прерывания печати следует нажать кнопку «ПУСК/СТОП».

6. По окончании записи электрограммы установите выключатель питания в положение «О». Снимите электроды с пациента.

7. Выключите прибор из сети, вырежьте часть ленты с полученными ЭКГ: фрагмент образца калибровочного сигнала и ЭКГ в стандартных отведениях и наклейте в тетрадь [2, с. 11].

В результате использования технологии модульного обучения по дисциплине «Физика, математика» у студентов первого курса наблюдается: положительная динамика уровня обученности и качества приобретённых знаний (по сравнению с прошлым годом, составила 92\%), а также возрос интерес к данной дисциплине (рис 1).

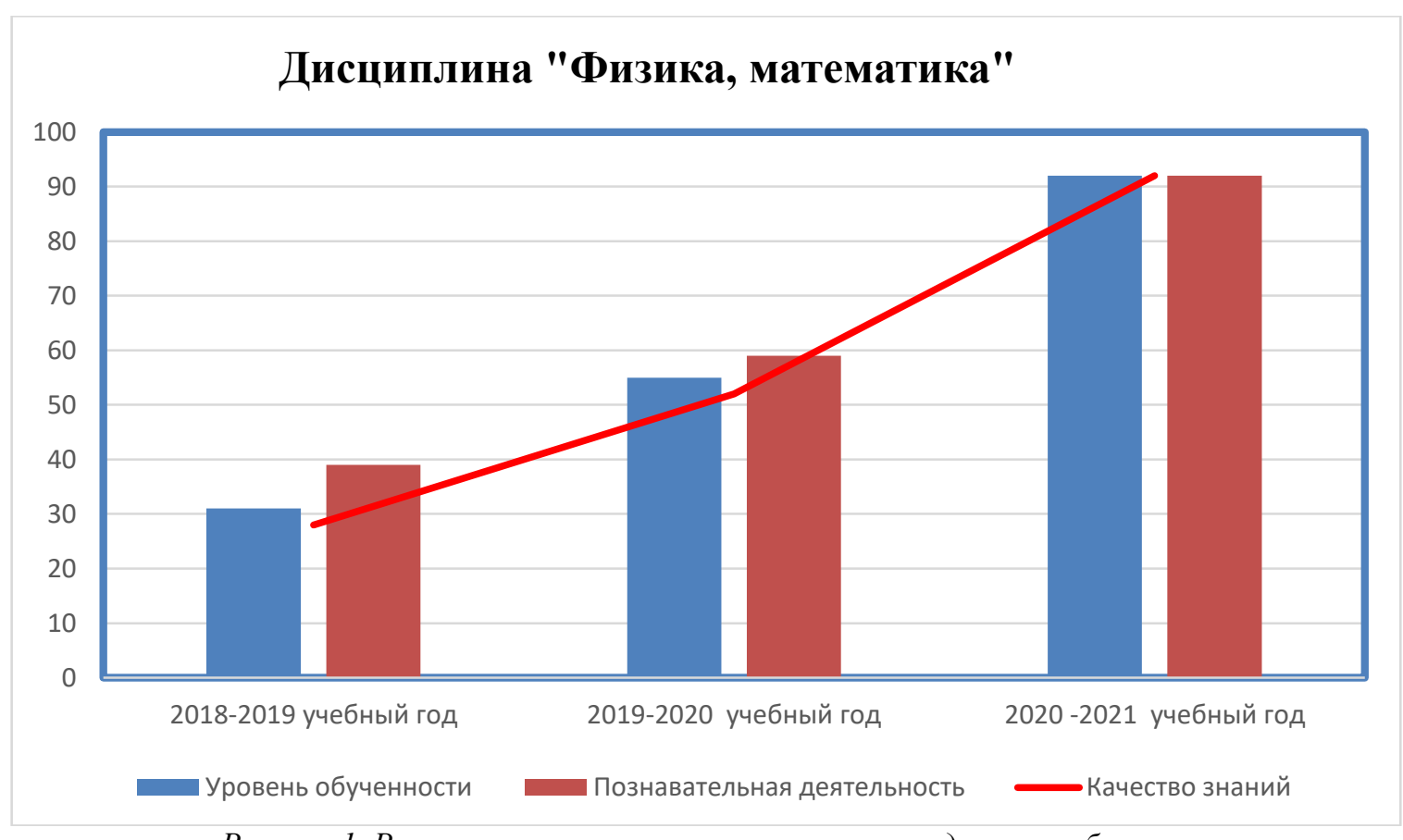

Рисунок 1. Результат использования технологии модульного обучения 
В заключении, необходимо выделить основные способы повышения процесса обучения:

- за счет использования современных технологий обучения;

- $\quad$ за счет активизации роли каждого обучающегося в учебном процессе.

Можно утверждать, что при изменении способа подачи учебных материалов, использовании современных технологий, различных форм и приёмов на занятиях по дисциплине «Физика, математика» - позволяет развить личностную заинтересованность и самостоятельность каждого студента к учебной деятельности, желанию понимать для чего эти знания необходимы будущему врачу, а также активизировать познавательную деятельность и память. Использование технологии модульного обучения приводит к увеличению качества знаний по дисциплине «Физика, математика».

$$
* * *
$$

1. Иванова О.Ю., Антонова Ю.Н. Технология модульного обучения иностранному языку как средство организации самостоятельной работы бакалавров// Проблемы лингвистики, методики обучения иностранным языкам и литературоведения в свете межкультурной коммуникации: сборник материалов II Международной научно-практической Интернет-конференции (27-28 февраля 2017 г.) / под ред. О.Ю. Ивановой. Орел: ФГБОУ ВО «ОГУ имени И.С. Тургенева», 2017. С. 185-189.

2. Плащевая Е.В., Нигей Н.В. Смирнов В.А., Лысак В.А. Лабораторный практикум по дисциплине «Физика, математика» раздел «Физика». Благовещенск, Амурская ГМА, 2020 г. С. 219.

3. Плащевая, Е. В. Методические особенности проведения лабораторных работ по физики в медицинском вузе / Е. В. Плащевая, Н. В. Нигей // Проблемы управления качеством образования: Сборник статей XIII Всероссийской научно-практической конференции, Пенза, 28-29 декабря 2020 года. - Пенза: Пензенский государственный аграрный университет, 2020. - С. 130-136.

4. Плащевая, Е. В. Особенности применения интерактивных методов обучения в курсе физики медицинского вуза / Е. В. Плащевая, Н. В. Нигей // Тенденции развития науки и образования. - 2021. - № 75-4. - С. 121123. - DOI 10.18411/lj-07-2021-147.

\section{Плащевая Е.В. \\ Формирование личности будущего врача в цифровом образовательном пространстве в процессе изучения медицинской информатики}

ФГБОУ ВО «Амурская государственная медищинская академия»

(Россия, Благовещенск)

doi: 10.18411/trnio-01-2022-150

\section{Аннотация}

В данной статье рассматривается и обосновывается необходимость использования цифровых технологий для развития личности будущего врача. Цифровая грамотность позволяют молодому врачу войти в информационную среду XXI века технологически компетентным специалистом и личностно развитым человеком. И самое главное современные студенты нуждаются в этой поддержке при включении их в цифровое образовательное пространство.

Ключевые слова: будущие врачи, цифровые технологии, образовательное пространство, студент, личность.

\section{Abstract}

This article discusses and justifies the need to use digital technologies for the development of the personality of a future doctor. Digital literacy allows a young doctor to enter the information environment of the XXI century as a technologically competent specialist and a personally developed person. And most importantly, modern students need this support when they are included in the digital educational space.

Keywords: future doctors, digital technologies, educational space, student, personality. 